\title{
Templos da Casa de Saul? Dissonâncias entre o registro bíblico e material
}

\author{
The Temples of the House of Saul? Dissonances \\ between the biblical and material records
}

\section{¿Los templos de la casa de Saúl? Diferencias entre lo registro bíblico y el material}

\author{
Silas Klein Cardoso***
}

\begin{abstract}
RESUMO
Dentre as mudanças advindas da transição entre Idade do Bronze e do Ferro, a ausência de templos na região montanhosa central retém um dos lugares de destaque. As páginas do texto bíblico que remetem ao período, contudo, apresentam diversos locais de culto na região do platô de Benjamim, principalmente ligadas à "casa" ou dinastia de Saul. O presente artigo, deste panorama, discute as dissonâncias entre as descrições bíblicas sobre locais de culto da "Casa de Saul" e aqueles encontrados no registro arqueológico do período. Ao reconfigurar o olhar sobre a questão, assumindo um conceito de religião moldado por aspectos midiáticos e sócio-comunicativos, baseados na materialidade e medialidade da religião, são propostos, do registro arqueológico, dois níveis de práticas religiosas, cada qual com seus respectivos locais de culto. Conclui-se que o texto bíblico utiliza memórias para compor seu retrato, essas alteradas em nuances para se adaptar ao enredo da história de Saul versus Davi.

Palavras-chave: Templos; Antigo Israel; História da Religião; Exegese do Antigo Testamento; Saul.
\end{abstract}

\begin{abstract}
Among the changes coming from the transition between the Bronze and Iron Age, the absence of temples in the Central Hill Country is prominent. The biblical text that refer to the period, however, present several places of worship in the region of Benjamin's Plateau, mainly linked to the Saulide "house" or dynasty. The present article, from this panorama, discusses the dissonances between the biblical descriptions about places of worship of the "House of Saul" and those found in the archaeological record of the period. In reconfiguring the view on the issue, assuming a concept of religion shaped by media and socio-communicative aspects, based on the materiality and mediality of religion, two levels of religious practices are proposed from the archaeological record, each with its respective places of worship. As conclusion, the articles argue that the biblical text uses memories to compose its portrait, which are altered in nuances to adapt to the larger plot in the history of Saul versus David.

Keywords: Temples; Ancient Israel; History of Religion; Old Testament Exegesis; Saul.
\end{abstract}

* Pesquisador pós-doutorando na Universidade de Berna (UBE, Suíça), Instituto de Estudos do Antigo Testamento. Doutor em Ciências da Religião (UMESP, Brasil). E-mail: silasklein@gmail.com.

** Agradeço à CAPES por possibilitar pesquisar na Universidade de Zurique, sob supervisão do Prof. Dr. Christoph Uehlinger, entre 2018/19 (PDSE: 88881.190593/2018-01). Também agradeço aos colegas e às colegas do projeto "Stamp Seals from the Southern Levant" (SNSF: CRSIIS_La6426) pelo ambiente intelectual privilegiado. Diversos indivíduos contribuíram com estágios prévios da pesquisa. Devo mencionar José A. Kaefer (UMESP), Christoph Uehlinger (UZH) e colegas de Forschungswerkstatt (UZH), Paulo A. S. Nogueira (PUC Campinas), Kátia Pozzer (UFRGS), Tércio M. Siqueira (UMESP), Cecilia Toselli (UMESP), e Carlos Eduardo Mattos (UMESP). Quaisquer erros, não obstante, são de minha responsabilidade. 


\section{RESUMEN}

Entre los cambios provenientes de la transición entre la Edad de Bronce y la de Hierro, la ausencia de templos en la región montañosa central conserva uno de los lugares prominentes. Sin embargo, las páginas del texto bíblico que se refieren a la época presentan varios lugares de culto en la región de la meseta de Benjamín, principalmente vinculados a la "casa" o dinastía de Saúl. El presente artículo, a partir de este panorama, discute las disonancias entre las descripciones bíblicas de los lugares de culto de la "Casa de Saúl" y las encontradas en el registro arqueológico de la época. $\mathrm{Al}$ reconfigurar el punto de vista sobre el tema, asumiendo un concepto de religión conformado por aspectos mediáticos y sociocomunicativos, basado en la materialidad y la mediatividad de la religión, se proponen dos niveles de prácticas religiosas a partir del registro arqueológico, cada uno con sus respectivos lugares de culto. Se concluye que el texto bíblico utiliza memorias para componer su retrato, que se alteran en matices para adaptarse a la trama más amplia de la historia de Saúl y David.

Palabras clave: Templos; Antiguo Israel; Historia de la Religión; Exégesis del Antiguo Testamento; Saúl.

\section{Introdução}

A região e o período que os textos bíblicos assinalam ao primeiro "rei" de Israel, Saul, é singularmente atrativa à pesquisa histórico-religiosa. De acordo com Blenkinsopp (1972, p. 68-69), há cinco templos na região, a saber: (1) santuário sem nome (1Sm 10.1); (2) gib’at häelobîm (1Sm 10.5, 10); (3) Gilgal (1Sam 11.15); (4) Mispa (1Sm 10.24); (5) Nobe (1Sm 22.19). ${ }^{2}$ Segundo padrões veterotestamentários, tal número é tão significativo quanto atípico, principalmente no contexto da chamada historiografia deuteronomista (HD), que enfatiza templos regionais solitários (KRATZ, 2010). A informação se torna ainda mais anômala se contraposta ao registro material que - a despeito de raras exceções na região costeira e de transição tardia, que possuem templos discerníveis (p.ex., Tell Qasille, Tell Abu Hawam, Beth-Shean V) - não

1 O termo usado em certas narrativas é "líder" (heb. nägîd, 1Sm 9.16; 10.1), que pode ser adição deuteronomista (McKenzie, 2006, p. 60-62) ou revelar as nuances religiosas do ofício. Para Hasel (1998, v. 9, p. 193) "no título 'rei', a ênfase primária está no elemento político, enquanto no título nāgî $\underline{d}$ os elementos religioso e sagrado permanecem no primeiro plano". De qualquer forma, a vocação de Saul, como os juízes (Jz 2.16, 18), é de salvar (heb. y̌s ) com libertação pontual frente aos filisteus (heb. pèlišthí cf. $2 \mathrm{Sm}$ 3.18). O clamor do povo (1Sm 9.16) é similar ao de Ex 3.7. Clamor (heb. șe ăââ), povo (heb. 'am) e ver (heb. $r$ ' $h$ ) só aparecem nesses dois versículos em toda a BH. A palavra clamor (heb. șé $\breve{a} q \hat{a})$, em si, surge apenas $2 \mathrm{x}$ na HD (1Sm 4.14; $1 \mathrm{Sm}$ 9.16) e sua raiz, $V_{s}{ }^{\prime} q$ apenas outras duas vezes referenciando o Êxodo (Js 24.7; Jz 10.11), talvez demonstrando reminiscências de tradição de Israel (norte). Ademais, o próprio vasilhame de unção, pak (1Sm 10.1), que pode ser um frasco ou botelha, só surge aqui e na unção de Jeú (2Rs 9.1, 3), outro líder com missão religiosa. As unções de Davi e Salomão são feitas com chifres de azeite (heb. qarněkã šemen, 1Sm 16.1, 13; 1Rs 1.39).

2 Langston (1998), contabiliza onze: (1) Jerusalem (?); (2) Geba/Gibeá; (3) Bete-Áven; (4) Betel; (5) Gibeão; (6) Gilgal; (7) Ramá; (8) Mispa; (9) Nob; (10) Quiriate-Jearim; (11) Anatote. Em adição, é possível que o oráculo de Moisés em Dt 33.12, onde diz que Benjamim descansa "entre os ombros" seja referência ao local entre locais de culto importantes, i.e., o templo de Betel e o templo de Jerusalém (OLSON, 2011, p. 868). 
rendeu templos no Ferro I3 (cf., p. ex., ZWICKEL, 1994, p. 204-39; ZEVIT, 2001, p. 124; KEEL; UEHLINGER, 2010, p. 150; SCHROER, 2018, p. 12; BERLEJUNG, 2019, p. 122-24). A dissonância entre registro bíblico e arqueológico é particularmente notável uma vez que colocada no contexto da transição ${ }^{4}$ entre a Idade do Bronze e Ferro, tempo que, consensualmente, viu estruturas de práticas religiosas serem alteradas. ${ }^{5} \mathrm{~A}$ informação ganha mais importância sendo este o tempo e o local de origem do (primeiro? segundo? ${ }^{6}$ ) Israel.

Uma pergunta sobressai: qual a razão para estudar os templos do domínio da "Casa de Saul", então? Não seria paradoxal perguntar sobre os templos se sua inexistência foi reiterada? Antes de responder à questão empiricamente, é apropriado respondê-la disciplinarmente, haja vista advir da Exegese Bíblica. Apesar das críticas precisas quanto ao uso de fontes secundárias na reconstrução da História de Israel (p. ex., UEHLINGER, 2001, p. 31-39; FINKELSTEIN, 2015, p. 65-68) e de clamores por um uso balanceado (NA'AMAN, 2010), textos bíblicos, mesmo quando tardios ou lendários, ditam questões de pesquisa na área. É por isso que, mesmo pesquisadores que dão às fontes primárias a devida importância, os templos

Utilizo nesta pesquisa a Baixa Cronologia, na qual as datas absolutas são: Bronze Tardio entre 15501125/1100 (IA: 1550-1450; IB: 1450-1350; IIA: 1350-1300/1275; IIB: 1300/1275-1250/1225; III: 1250/1225-1125/1100); Ferro I-IIA entre 1125/1100-800/775 (IA: 1125/1100-1050; IB: 1050-1025; IC: 1025-950/925; IIA antigo: 950-925/875; IIA tardio: 875-800/775). A associação entre Ferro IB/ IC é aproximada pela baixa resolução dos vestígios. Nesse aspecto, convém dizer que, dentre as obras citadas, há algumas escritas antes da "baixa cronologia" de I. Finkelstein ser proposta (i.e., ZWICKEL, 1994; KEEL; UEHLINGER, 2010 [1992; neste caso, cf. p. 482-484]). Por isso, há menção que a referida ausência de templos ocorreu no Ferro IIA. Isso não ocorre em obras recentes que adotam a baixa cronologia, cujo período de ausência seria Ferro I. Nas demais obras que alocam a ausência no Ferro IIA utiliza-se a cronologia convencional revisada por A. Mazar.

4 Hoje a transição é explicada, mais do que pela invasão dos chamados "povos do mar", por uma conjunção de fatores distintos, que vão desde alterações climáticas, desastres naturais (p.ex., terremotos), invasões, fome, colapso econômico, entre outros (cf. GILBOA, 2013, p. 624-48; KILLEBREW, 2013; CLINE, 2014).

5 Outra característica é a ausência de tumbas, considerada por Kettler (2002) um meaningful phenomenon.

${ }^{6}$ Knauf (2016) utilizou as perguntas para denotar o hiato entre as evidências históricas dos inícios de Israel, primeiro na menção a "Israel" do Faraó Merneptah e, depois, para a unidade política que gerou um estado que adotou o nome "Israel", possivelmente no platô de Benjamin sob Saul, filho de Quis. Finkelstein (2019), apoiando-se na teoria de Knauf, procurou os inícios de Israel através das evidências arqueológicas.

7 O termo "casa de Saul" (heb. bêt $̌ s a ̂$ 'ull), traz a ideia de dinastia, podendo ser traduzido como "dinastia Saulida”. Essa seria contraposta à dinastia davídica, i.e., à "casa de Davi” (heb. bêt dāwid) na transição entre Ferro IC para Ferro IIA (cf. 1Sm 3.1, 5; KNAUF; GUILLAUME, 2016, p. 62-76). As memórias bíblicas são unânimes em afirmar a primazia militar saulida frente à davídica, o que parece indicar resquícios de memória histórica, visto que toda a ideologia da redação desses textos tardios tem como foco a região ao redor de Jerusalém. 
do Ferro I-IIA em Canaã, onde existiu Israel e Judá, continuam sendo discutidos (p. ex., ZWICKEL, 1994; SILVA, 2018; FINKELSTEIN, 2020). O “mundo bíblico”, afinal, não está apenas “"atrás” ou 'na frente' do texto, mas no próprio texto" (CORNELIUS, 2017, p. 195, tradução nossa ${ }^{8}$ ). Anacronismo? Talvez. Contudo, é possível argumentar que, além do anacronismo marcar a audácia do bistoriador (LORAUX, 1992, p. 58) e operar para a inovação historiográfica (CARDOSO, 2019, p. 36), é papel do historiador da religião "confrontar o mito com o que podemos razoavelmente assumir sobre tempos e lugares a que ele se refere" (KNAUF, 2016, p. 125).

Às questões disciplinares, devem ser adicionadas as razões empíricas para o estudo. Nisso, o ineditismo de seu recorte torna-o relevante. Históricogeograficamente, os locais de culto do platô de Benjamim no Ferro I-IIA foram relativamente pouco explorados no passado (SCHUNCK, 1963; 1992; BLENKINSOPP, 1972; LANGSTON, 1998). A razão para o lapso de explorações localizadas nesse tempo e espaço é, antes de tudo, teóricoconceitual. A subdisciplina que insistem chamar "História da Religião do Antigo Israel" (mas veja NOLL, 2007, 2013), possui imperativos que tornam seus argumentos circulares. A título de exemplo, poucos ainda consideram o "Israel Bíblico" de forma adequada, i.e., como construção literária (DAVIES, 2015). Tal desatenção, por vezes, impõe às análises quadros metodológicos inapropriados, estes ainda simplificados com polarizações conceituais (STAVRAKOPOULOU, 2013; UEHLINGER, 2015; 2019) e tertia comparationis amplas. Como resultado, o texto bíblico deixa de ditar questões de pesquisa para ditar seus resultados.

De um ponto de vista teórico, é importante assinalar que o próprio conceito de religião tem sofrido ataques nas últimas décadas (p. ex., KING, 2017), estes estendidos à História Antiga (p.ex., ROUBEKAS, 2019) e do “antigo Israel” (p. ex., CARDOSO, 2020a; MANDELL; SMOAK, 2019). Com isso, tornou-se mais complexo visualizar "religião" nas fontes. Sem os paradigmas cristão-ocidentais que regiam os conceitos "clássicos" - i.e., autoevidentes e acríticos -, "religião" deixa de ser a busca pelo "Deus" (maiúsculo, singular e masculino) e seu Templo (maiúsculo e singular), para buscar "práticas religiosas". Há incontáveis páginas que ofereceram soluções para o problema, mesmo antes do conceito religião se tornar insustentável. Pesquisadoras e pesquisadores reformataram a disciplina com novos olhares (p. ex., NIDITCH, 1997; ZEVIT, 2001), integrando fontes distintas (p. ex., KEEL; UEHLINGER, 2010; SCHROER, 2018) e utilizando novos enfoques sócio-religiosos (p. ex., ALBERTZ; SCHMITT, 2012). A presente pesquisa,

Todas as obras originalmente publicadas em outros idiomas foram traduzidas pelo autor. 
assim, se justifica por investigar a questão abandonando explicitamente o conceito ocidental-cristão de religião para conceber religião enquanto rede de práticas que se molda por aspectos midiáticos e sócio-comunicativos localizados no tempo e espaço, algo que já foi chamado de "redes mágicomíticas"(CARDOSO, 2019).

A pergunta que se pretende responder é sobre a presença e a configuração de locais de culto no platô de Benjamimª na Idade do Ferro I-IIA, dando atenção à dissonância entre registros bíblicos e materiais. Isso implica questionar não apenas estruturas arquitetônicas que seriam, stricto sensu, templos, mas locais que abrigam práticas religiosas. É oportuno dizer aqui que é justamente essa dissonância entre fontes textuais e materiais que torna o tema apropriado para um dossiê sobre "Cultura Material e Cultura Visual Religiosas". Enquanto um tema bíblico possa, à primeira vista, parecer deslocado, é justamente em campos textocêntricos que a adesão de uma perspectiva material ganha fôlego. Nisso, em perspectivas recentes, já abrigadas sob títulos como material religion (MEYER et al., 2010) ou religion as mediation (MEYER, 2020), pensar materialmente não consiste em ver como a religião é expressa de forma material, mas em observar como a religião se dá de forma material. O quadro está além da intelecção linguístico-conceitual, interrogando não apenas a função de artefatos, mas seu significado e, mais, seu impacto sócio-cultural e psicológico (HODDER, 1995, p. 11, 22-24; cf. MILLER, 2005, p. 5). A pesquisa, logo, desnuda limites de uma abordagem puramente filológica da História da Religião de Israel, tal qual fornece possíveis caminhos para sua integração.

\section{Os templos de Benjamim, segundo os relatos bíblicos}

A partir de uma seleção de três textos considerados significativos a saber, Jz 3.12-30; $1 \mathrm{Sm} 9-10 ; 1 \mathrm{Sm} 20.24-34^{10}$-, a memória bíblica faz referência explícita a duas categorias de locais que abrigavam práticas religiosas, santuários regionais (heb. bāmôt) e tumbas (heb. qǔbûrâa), ${ }^{11}$ além da possível existência de um terceiro, para práticas a céu-aberto (heb. gilgāl).

\footnotetext{
Este delimitado à área entre Tel en-Nasḅeh (norte), Tell el-Ful (sul), Jeba (leste) e el-Jib (oeste).

10 Não há textos bíblicos do período (SCHNIEDEWIND, 2013; SASS; FINKELSTEIN, 2013; 2016), dificultando sua utilização como "fontes" (UEHLINGER, 2001, p. 31-39), mas há "memórias" (ASSMANN, 1997, p. 8-9; cf. ASSMANN, 2008) que podem remontar fragmentos do período. A seleção considera tradições e retratos, stories ou outlines, cujos indícios contrapõem retórica ou ideologicamente o contexto literário.

11 É válido notar que textos como $1 \mathrm{Sm}$ 9-10 utilizam santuários e tumbas de forma similar. Impera o sentido de "local de prática de culto" e não "estrutura arquitetônica". O imaginário comum também é revelado pela metáfora de "casa" (heb. bayit), casa de deuses/as ou mortos, e "local" (heb. mäqốm) de deuses/as e mortos.
} 
Os textos que refletem o período de chefatura de Saul, 1Sm 9.1-10.16; 20.24-34, refletem santuários regionais (heb. bāmôt). Embora na história compósita (1Sm 9-10) o relato de procura das jumentas ${ }^{12}$ e resultante procissão (1Sm 10.-2-7, 9-13) tenha fins legitimatórios, tanto na apresentação dos limites dos domínios de Saul (cf. 1Rs 1) e dom divinatório ${ }^{13}$, é possível que a descrição da bāmâ e seus ritos reflita a concepção do lugar de culto de famílias extensas (heb. bêt 'äbôt) tal qual $1 \mathrm{Sm}$ 20.24-34. Ambos utilizam estruturas cobertas, com uma liškâa (heb. cômodo; cf. 1SmLXX 1.18, gr. katalyma), estão dentro da estrutura da cidade (heb. 'î), tendo sacrifícios realizados por divinador local, provavelmente sob a alcunha "vidente" (heb. rōe). A estrutura sócio-política fazia banquetes serem organizados por posição clânica, i.e., o paterfamílias tinha assento privilegiado, com familiares na sequência (1Sm 9.22; 20.25), o que indica utilização de mesa (heb. šulhān) e assentos (heb. mwšbwt), embora não haja descrições dos objetos. Sacrifícios também implicam o aparato para tal atividade, como $1 \mathrm{Sm} 9$ aponta com: local de abate, cerâmicas para preparar alimentos, facas, e um cozinheiro ou açougueiro (heb. tabbāh, 1Sm 9.23), que respondia diretamente ao chefe do sacrifício.

Como práticas, é razoável supor que o sacrifício (heb. zebah) ocupasse lugar central. Mesmo na história de Eúde, a metáfora é sacrificial. ${ }^{14}$ É possível que o sacrifício periódico familiar (heb. zebah hayyāmîm/mišpăhâa, 1 Sm 20.6, 29) e hoōešs (heb. [festival da] Lua Nova) fossem celebrados no local. Também parece certo assumir práticas divinatórias, i.e., de comunicação entre seres humanos e sobrenaturais. Os relatos trazem o vidente (heb. rō'e) que entrega oráculos cotidianos (1Sm 9.6-10) e específicos, i.e., no contexto de preocupações dos habitantes da cidade (1Sm 16-21; 10.1-8), prática pela qual eram pagos (heb. těšûrâ?). É possível que rituais de purificação também

12 Que, possivelmente, carrega tanto conotações de status social (Jz 5.10; 10.4; 12.14; 2Sm 16.2), quanto divinatórios (Nm 22: 22-35; 1Sm 9!) (SCHROER; KEEL, 2005, p. 190-191).

13 I.e., pela pergunta "está Saul entre os profetas" (heb. hăgam šă $\hat{u} l$ bannĕbî̀ $̂ m$ ), tal qual a pergunta retórica: "e quem é o pai deles?” (heb. himî 'ăbîhem; cf. 2Rs 2.12; 6.21; 13.14), cuja resposta deve ser entendida como Saul, apontando para seu papel de líder profético e, talvez, religioso (McCARTER Jr., 2008, p. 184).

14 O campo semântico e duplos-sentidos revelam isso: (1) Eglom (heb. tourinho) que é "gordo" (heb. bärî); (2) os verbos “oferecer" (heb. qrb) e "oferta” (heb. minhâa); (3) "imagens" (heb. pāsîl) e o gilgäl remetem a santuários; (4) "coxa” (heb. yārēk); (5) a expressão oracular "palavra de 'ělōhîm” (heb. děbar'ĕlōhîm); (6) o termo "gordura” (heb. hẹeleb) utilizado para animais de sacrifício etc. Eúde é mercenário/ canhoto (heb. 'îs 'itțer yad-yĕmînōw, Jz 3.15, 21), vestido de vestes sacerdotais (heb. mad, Jz 3.16), com ofício profético (Jz 3.20) e imola o "tourinho" deixando sua gordura (heb. ḥeleb, a "melhor parte", Gn 45.18; Dt 32.14) encobrir a lâmina. 
fossem desempenhados, como a expressão "por acaso ele não [está] puro" (heb. miqre hî̀ biltî țāhōwr, 1Sm 20.26 [4QSamb]) indica.

\section{Tumbas (beb. qĕbûrâ)}

Embora surjam como cenário para a "procissão real" de Saul, o texto de 1Sm 9-10 apresenta duas tumbas. O nome dos locais, tumba de Raquel (heb. qĕburat rähẹ̄) e Carvalho de Tabor/Debora? ${ }^{15}$ (heb. 'étôwn tābōwr/dëbōwrâ?), remetiam à celebração da morte das figuras que, na tradição bíblica, eram matriarcas ancestrais ligadas à região. As demais referências na $\mathrm{BH}$ aos locais denotam presença de colunas memoriais (heb. mașşêbôt) nos locais, coadunando ao padrão oeste-semítico de erigir colunas em memória dos antepassados em santuários regionais (2Sm 18.18; cf. CAT 1.17:1.26-27). Raquel, em outros textos associada aos tëräpîm (Gn 31.19, 34-35), também pode indicar que essas imagens de ancestrais tivessem espaço nas tumbas. Assim, são sugeridas práticas ligadas à memória/presença dessas ancestrais e, possivelmente, rituais de lamento (invocação?) e divinação. ${ }^{16}$ Aliada a isso, a presença de duas matriarcas ligadas ao ciclo de vida pode denotar, como argumentou Stavrakopoulou (2012, p. 97), a crença que a morte das personagens gerava vida, moldando o culto à vida e fertilidade.

\section{Santuários abertos (heb. gilgāl)}

Gilgal é mencionado em Jz 3.12-30 e 1Sm 9.1-10.16. É difícil saber o que o termo representa. ${ }^{17}$ Parece seguro afirmar que se tratava de santuário

15 Para Toorn (1996, p. 216) tābōwr é corrupção de děbōwrâ, da ama de leite (heb. mêneqet, Gn 35.8) de Raquel. Se correto, este éo Carvalho de Débora de Gn 35.8, chamado 'allöwn bäkût (heb. "Carvalho do Lamento").

${ }_{16}$ gilgäl era, provavelmente, um círculo (pela raiz $\sqrt{g l l}$, i.e., "rolar", "ser rolado") de pedras (cf. Js 4.1921), que marcavam um lugar de culto ou de reunião popular, talvez com o propósito de oferecimento de sacrifícios (Os 4.15; 9.15; Am 4.4). O termo foi associado a uma série de sítios cuja estrutura é similar à descrita. Zertal $(2008$, p. 83-84, 111) identificou, em seus levantamentos arqueológicos, uma série de sítios com formato de pegadas humanas, do qual el-Unuq se destaca. Para Finkelstein (2016, p. 102), o termo na história de Eúde é uma adição para deixar claro o sentido religioso das pěsillim (heb. imagens). A associação do lugar ao território benjaminita talvez tenha provocado seu uso, visto que, além de estar próximo a Jericó, no território de Israel, Betel e Gilgal surgem frequentemente associadas nos oráculos de Oséias $(4.15 ; 9.15 ; 12.12)$ e Amós $(4.4 ; 5.5)$.

17 É oportuno mencionar aqui1Sm 28, que fala da consulta (heb. $d r s$ ) de Saul pela "senhora dos fantasmas" (heb. 'ěšet ba 'ălat-'ōwb, 1Sm 28.7), que ficava ao norte de Samaria, En-Dor (Js 17.11). Apesar de que na forma final o texto tenha sido organizado de forma polêmica (cf. 1Sm 15.23/Dt 18.10-11) contra Saul, o oráculo do Samuel divinizado se dá no nome de $y$ bwh e é certeiro (HAMORI, 2015, p. 130). Após o oráculo, a necromante sacrifica (heb. $z b h$ h $1 \mathrm{Sm} 28.24$ ) por Saul e seus homens. Na memória de Judá, Saul e, provavelmente, os benjaminitas de forma geral, consultavam os mortos, outro rito que poderia ter lugar em tumbas. 
aberto (p. ex., Js 4.19-24), utilizado para festivais (p. ex., Js 5.10-12). Embora sua adição seja suspeita, podendo refletir escrita posterior (Jz 3.19; 1Sm 10.8; cf. Js 2.1; $1 \mathrm{Sm} 11.14 ; 13.4,8,12)$, sua menção geralmente está ligada a sacrifícios (Os 4.15; 9.15; 12.12; Am 4.4; 5.5). Em Jz 3, o local é descrito com a presença de pĕsîlîm (heb. "imagens") e, em 1Sm, o termo parece evocar a imagem de um lugar aberto de assembléia (1Sm 11:14-15; 13.8-15). É possível que a menção ao profeta (heb. nābî) ou ao bando de profetas (heb. hebel-nĕbi'îm) que atuavam fora dos santuários locais (heb. bāmôt), i.e., fora da cidade, sob êxtase e música, tivesse parte nesses centros.

\section{Os templos de Benjamim, segundo a cultura material}

O registro material ${ }^{18}$ produz uma taxonomia distinta de locais de culto. Antes de descrevê-los, contudo, é importante assinalar a dificuldade em identificar locais de culto pelo registro material. Geralmente, são identificados por padrões de atividades e arquitetura. ${ }^{19}$ Para fazer tal descrição utiliza-se neste artigo o conceito de coleções de artefatos rituais ${ }^{20}$ e a classificação de utilização dos objetos ${ }^{21}$ (cf. ALBERTZ; SCHMITT, 2012, p. 57-74).

18 Foram considerados os sítios: (1) Beitin (KELSO, 1968; cf. FINKELSTEIN; SINGER-AVITZ, 2009); (2) el-Jîb (DAJANI, 1953; PRITCHARD, 1962); (3) et-Tell (CALLAWAY, 1976, 1993a; FINKELSTEIN, 2007; MARQUET-KRAUSE, 1948); (4) Kh. Abū-Musarrah (PELEG; YEZERSKI, 2004); (5) Kh. ed-Dawwara (FINKELSTEIN, 1990); (6) Kh. Nisieh (LIVINGSTONE, 2012; cf. LEHMANN; VARONER, 2018); (7) Kh. Raddana (CALLAWAY, 1993b; cf. LEDERMAN, 1999); (8) Tell el-Fûl (LAPP, 1993; cf. FINKELSTEIN, 2011); (9) Tell en-Nasḅeh (WAMPLER, 1947; McCOWN, 1947; cf. ZORN 1993a, 1993b). Para o histórico ocupacional, cf. CARDOSO, 2019, p. 177-96. Sítios da região sem camadas do Ferro I-IIA: El-'Eizariya, El-Qubeibeh, Kh. Hayian, Nebi Samwil, Kh. Shilha. Kh. Qeiyafa não foi considerada pela distância, enquanto Moẓa e Deir el-'Azar (Kh-Jearim) pelo estágio inicial das escavações científicas.

19 Renfrew e Bahn (2016, p. 413-20) dizem que o reconhecimento de tais padrões e atividades, se dá por quatro componentes: (1) foco de atenção, pressupondo que rituais exijam um alto envolvimento, este que pode ser notado por locais de associações peculiares (edifício separado, equipamento ritual, símbolos repetidos); (2) zona fronteiriça deste mundo com o além-mundo, assumindo divisões entre o "natural" e "sobrenatural", que podem ser notados com áreas de rituais, conceitos dicotômicos etc.; (3) presença da(s) deidade(s), pressupondo a presença material ou imaterial da divindade, esta notada por imagens cúlticas, símbolos, ritos etc.; (4) participação e oferendas, pressupondo que rituais envolvem presentes aos seres celebrados, equipamentos para induzir à experiência religiosa (como, p. ex., música, dança, êxtase), animais sacrificados, comida e bebida votivas, riquezas na produção dos materiais relativas à condição social dos celebrantes etc.

20 I.e., "concentrações localizadas de vestígios de cultura material religiosamente significantes" (HOLLADAY, 1987, p. 282, n. 1).

21 Que consiste em dividi-los entre: (a) artefatos não funcionais que sugeririam funções cúlticas (p. ex., incensários, altares em miniatura, estatuetas etc.); (b) artefatos "pessoais", i.e., que não carregam aspectos tipicamente religiosos, mas que foram encontrados em coleções de artefatos considerados religiosos (p. ex., vasilhames de luxo, objetos de adorno pessoal, peças de jogos etc.); (c) artefatos funcionais. 
A partir disso, é possível encontrar duas esferas de locais de culto, com diferentes inclinações: (1) esfera familiar, com espaços domésticos e funerários; e (2) esfera comunitária. A diferenciação entre os espaços não é simples, haja vista a própria configuração da região como chefatura complexa ser regida por laços familiares (MILLER II, 2005; cf. LEHMANN, 2004). Embora a diferença entre os níveis se dê pela estrutura arquitetônica e por focos principais de práticas rituais, suas fronteiras devem ser consideradas fluidas. Abaixo, possíveis locais de culto são enumerados e, na sequência, uma interpretação geral é fornecida.

\section{Esfera familiar}

Dentre a esfera familiar as preocupações e ritos seguem interesses da família nuclear, sendo de ordem regular (ligadas a ciclo de anos, meses, dias, ritos de passagem) e/ou intervencional (p.ex., doença, infertilidade, perigos etc) (MEYERS, 2013, p. 123-130). Há no registro oito locais que possivelmente abrigavam práticas religiosas domésticas.

Beitin Locus 315 (KELSO, 1968; cf. ALBERTZ; SCHMITT, 2012, p. 84-85)

$\begin{array}{lll} & \text { Funcionais } & \begin{array}{l}\text { Cálices e tigelas. } \\ \text { Artefatos }\end{array} \\ & \text { Não funcionais } & \begin{array}{l}\text { Estatueta antropomórfica, estatuetas } \\ \text { teriomórficas. }\end{array} \\ \text { Outras } & ----\end{array}$

O local, possivelmente residencial (CARDOSO, 2019, p. 188), seria de culto pela descrição dos achados (ALBERTZ; SCHMITT, p. 84-85). Entretanto, além de ser impossível encontrar o cômodo nos planos do sítio, ${ }^{22}$ não há desenhos ou fotografias da maioria dos itens descritos (cf. KELSO, 1968, p. 113, 115-116, 118, 121, 127). Embora a coleção seja pequena, os objetos parecem refletir eventos do ciclo diário, como alimentação, enquanto as estatuetas ${ }^{23}$ sugerem ritos de cura (DARBY, 2014).

22 Talvez pela limpeza realizada por fazendeiros antes das escavações de 1954 (KELSO, 1968, p. 87-88).

23 (a) torso de Astarte de $6 \mathrm{~cm}$ (n. 1011); (b) parte traseira e rabo de touro (n. 1004; parecida com o pl. 45:16);

(c) duas partes dianteiras de animais, provavelmente touros (n. 1008, 1028) (KELSO, 1968, p. 88, 116). 


\begin{tabular}{|c|c|c|}
\hline \multirow{3}{*}{ Artefatos } & Funcionais & ----- \\
\hline & Não funcionais & $\begin{array}{l}\text { Estatueta antropomórfica, Baal com braço } \\
\text { estendido. }\end{array}$ \\
\hline & Outras & ----- \\
\hline \multicolumn{2}{|c|}{ Práticas religiosas } & $\begin{array}{l}\text { Rito de cura (?), divinação (?), rito apotropaico } \\
\text { (?) }\end{array}$ \\
\hline \multicolumn{2}{|c|}{ Contexto religioso } & Eventos intervencionais, apotropia. \\
\hline
\end{tabular}

A Área I da escavação de 1934 encontrou um fragmento que foi interpretado como estatueta de Baal com braço estendido (KELSO, 1968, p. 84; cf. p. 116, pl 45:14). Embora pareça se tratar de figura humana, não é possível avançar com a interpretação iconográfica pela figura fragmentada registrada no relatório. O local provavelmente compôs um conjunto de salas de uma casa de quatro cômodos (i.e., $L 32,34,35,37,38,42$ ) e rendeu uma série de achados no L42, sendo possível local de armazenamento. ${ }^{24} \mathrm{~A}$ evidência, apesar de frágil, pode apresentar local de práticas religiosas no âmbito doméstico, envolvendo alimentação e ritos intervencionais.

El-Jîb Tumba 3 (DAJANI, 1953; PRITCHARD, 1963, p. 10; ESHEL, 1987)

\begin{tabular}{lll}
\multicolumn{1}{c}{$\begin{array}{l}\text { Funcionais } \\
\text { Artefatos }\end{array}$} & Tigelas, cálices, botelhas, cântaros, lâmpadas. \\
& Pessoais & $\begin{array}{l}\text { Brincos, braceletes, tornozeleiras, pregadeiras, } \\
\text { fechos de roupas, flechas, lanças, selos. }\end{array}$ \\
Práticas religiosas & $\begin{array}{l}\text { Libações, oferendas, alimentação (?), } \\
\text { adivinhação (?), ritos apotropaicos (?). }\end{array}$ \\
Contexto religioso & $\begin{array}{l}\text { Ciclo de vida (morte), além-mundo, apotropia, } \\
\text { iluminação além-vida (?). }\end{array}$
\end{tabular}

A caverna simples foi utilizada por múltiplas gerações e tem, como diferencial, o excesso de lâmpadas, 223 (1953, p. 66), que em muito ultrapassa necessidades funcionais, podendo conotar ligações com algum rito que ali fosse praticado.

\footnotetext{
242 alças de jarra (KELSO, 1968, p. 112; pl. 72); tigela mal polida (KELSO, 1968, p. 103; pl. 60:16); 13 potes de cozimento (KELSO, 1968, p. 101-102); 4 jarras de armazenamento (KELSO, 1968, p. 100-101); além de 2 sovelas de calcário (ing. limestone awls) (KELSO, 1968, p. 85, 126).
} 

Funcionais
Artefatos
Não funcionais
Pessoais
Práticas religiosas
Contexto religioso
Tigelas, cálices, potes de cozimento, pyxis, frascos, botelhas, cântaros, jarros de armazenamento, lâmpadas, rebolo.
Tigela de bronze, brincos, anéis, pingentes, pingente de osso, miçangas, pregadeira, peso.
Libações, oferendas, alimentação (?), adivinhação (?), ritos apotropaicos (?).
Ciclo de vida (morte), além-mundo, apotropia.

A caverna complexa de Abū-Musarrah, além de ser utilizada por múltiplas gerações, apresentou corpos virados com pés ao oeste e cabeça a leste, o que pode ter relação com a cosmovisão dos habitantes. Os itens pessoais revelam status dos habitantes.

Nisieb Tumba 65 (LIVINGSTONE, 2002; 2012, p. 51-64)

$\begin{array}{ll}\text { Funcionais } & \begin{array}{l}\text { Pote cozimento, lâmpada, jarras e botelhas. } \\ \text { Escaravelho, conóide, discos de basalto furados, } \\ \text { Nantefatos funcionais } \\ \text { conchas do mar, ossos, dente de gado de porte } \\ \text { pequeno. } \\ \text { Bracelete de bronze, pregadeiras, anéis, } \\ \text { miçangas, pingentes, pederneira. }\end{array} \\ \text { Práticas religiosas } & \begin{array}{l}\text { Libaces, oferendas, alimentação (?), } \\ \text { adivinhação (?), ritos apotropaicos (?). } \\ \text { Ciclo de vida (morte), além-mundo, apotropia. }\end{array}\end{array}$

Único achado arquitetônico do Ferro I/II do sítio (LIVINGSTONE, 2012, p. 51-64) e provavelmente utilizado até o Ferro IIA (LEHMANN; VARONER, 2018, p. 256). A caverna é conectada ao complexo de cavernas do Bronze. Certos itens encontrados (pingente humano, concha do mar, dente animal etc.) parecem refletir apotropia.

Tell en-Nasḅeh Tumba 32 (McCOWN, 1947, p. 77-100)

$\begin{array}{lll} & \text { Funcionais } & \text { Tigelas, cálices, cântaros, botelhas, jarras, } \\ \text { Artefatos } & \text { Não funcionais } & \text { lâmpadas, ânforas. } \\ & \text { Pessoais } & \text { Pregadeiras, escaravelhos, conóides. } \\ \text { Práticas religiosas } & \text { Libações, oferendas, alimentação (?), } \\ \text { Contexto religioso } & \text { adivinhação (?), ritos apotropaicos (?). } \\ \text { Ciclo de vida (morte), além-mundo, apotropia. }\end{array}$


Dentre os 792 objetos encontrados na T32, apenas 119 são apresentados no relatório (ZORN, 1993b, p. 12). A caverna natural é vista como lugar de práticas religiosas pela sua natureza e pela iconografia dos conóides e escaravelhos encontrados.

Tell en-Nasbeh Tumba 54 (McCOWN, 1947, p. 77-100)

$\begin{array}{lll} & \text { Funcionais } & \begin{array}{l}\text { Tigelas, cálices, cântaros, botelhas, jarras, } \\ \text { lâmpadas, ânforas. }\end{array} \\ \text { Artefatos } & \begin{array}{l}\text { Não funcionais } \\ \text { Pessoais }\end{array} & \begin{array}{l}\text {---- } \\ \text { Pregadeiras, escaravelhos, conóides. } \\ \text { Práticas religiosas }\end{array} \\ \text { Libações, oferendas, alimentação (?), } \\ \text { adivinhação (?), ritos apotropaicos (?). }\end{array}$

Os achados da T54 foram modestos, 400, e não foram encontrados esqueletos in loco, pelos assaltos à tumba. O alto número de objetos de pederneira fez os escavadores sugerirem uso (posterior) como habitação (McCOWN, 1947, p. 82-83).

Tell en-Nasbeh Room 616/622 (ALBERTZ; SCHMITT, 2012, p. 157-159; McCOWN, 1947, p. 233, 254, 303; ZORN, 1993b, p. 653-656)

$\begin{array}{lll}\text { Artefatos } & \begin{array}{l}\text { Funcionais } \\ \text { Não funcionais } \\ \text { Pessoais }\end{array} & \begin{array}{l}\text { Tigelas, lâmpadas de pé-alto, fogueira. } \\ \text { Suportes cúlticos, estatuetas antropomórficas. } \\ \text { Caveira (?), morteiro cosmético. }\end{array} \\ \text { Libações, oferendas, alimentação (?), } \\ \text { adivinhação (?), ritos apotropaicos (?). }\end{array}$

O local, parte de uma casa de quatro cômodos (Building 142.04 = R616, 619, 622, 623; ZORN, 1993b, p. 653-56; cf. ALBERTZ; SCHMITT, 2012, p. 157-59) tem layout centrado em fogueira, sendo um possível lugar de culto residencial que, depois, foi transformado em local de culto comunitário (cf. abaixo). Os utensílios denotam tal utilização ritual, especialmente o crânio humano, suporte cúltico próximo à fogueira, cálices e estatuetas. Provavelmente, eram realizadas práticas intervencionais (p.ex., cura, pelas estatuetas) e recorrentes (p.ex., apotropia).

Os espaços domésticos (Beitin L315; Beitin L44; Nas $\square$ eh R616/622) parecem ter sido palco de ritos intervencionais e do ciclo de vida. Isso é 
visto pelo uso de estatuetas antropomórficas em Beitin L315, Beitin L42/44 e, talvez, Nasḅeh R616/622, sugerindo ritos de cura (cf. DARBY, 2014). Possivelmente, ritos apotropaicos também tinham lugar, haja vista em Beitin L315 ter sido encontrado um penduricalho de osso humano e em Nasbeh R616/622 uma caveira. Talvez a isso estejam relacionados certos itens de adorno, como o morteiro de Nasḅeh R616/622 e pingentes e anéis de Beitin L315. É coerente sugerir refeições, o que o armazém próximo de L42/44, os cálices e tigelas de Beitin L315 também parecem reforçar.

Os espaços funerários (el-Jîb T3; Musarrah; Nisieh T65; Nasḅeh T32, 54) evidenciam aristocracia rural, pela qualidade dos itens e importações, além de estarem ligados aos modelos sociais centrados em famílias, onde a tumba corresponderia à concepção de "lar" (LEHMANN; VARONER, 2018, p. 261, 263), ao contrário dos estratos posteriores de el-Jîb e Nasḅeh, que mudam o layout das tumbas. A utilização religiosa desses espaços parece certa, haja vista unir diferentes gerações da família extensa sobre o mesmo teto e possui evidências de alimentação conjunta. As práticas religiosas, contudo, não são claras. Rituais apotropaicos podem ser sugeridos por certos escaravelhos e é possível enxergar traços de necromancia. Com relação ao último, parece conveniente associar os objetos cosméticos encontrados em algumas tumbas e as lâmpadas que excediam em muito necessidades funcionais à comunicação com os ancestrais (esp. el-Jîb). De igual modo, parece suficientemente seguro afirmar que havia comensalidade com os mortos, representada pelos vasilhames de libações e oferendas.

\section{Esfera comunitária}

Nesses locais, as preocupações estavam ligadas à vila e cidade, como produção de alimento e demais preocupações sócio-políticas. Não há, segundo a interpretação aqui expressa, necessidade de dividir entre "santuários de vizinhança" e "santuários locais e de vila" (cf. SCHMITT, 2014, p. 271-273, tipos III e VA). Assim, nessa esfera é possível assinalar:

Et-Tell Locus 65/69 (MARQUET-KRAUSE, 1949, p. 23)
Funcionais
Vasilha, cálices, jarro de armazenagem,
Artefatos
Não funcionais Suporte cúltico, estatuetas teriomórficas.
Pessoais
Chocalho, miçangas, esferas de argila.
Práticas religiosas
Libações, oferendas, alimentação (?), adivinhação (?), música, cosmética.
Contexto religioso 
O local é o mais claro espaço comunitário do registro. O suporte cúltico encontrado em um banco, este perfeitamente alinhado ao eixo lesteoeste, além da conjunção com outros vasilhames e estatuetas, cooperam com a interpretação. Possivelmente, eram realizadas refeições (pratos e cálices), libações (suportes cúlticos e cálices) e oferendas (itens cosméticos e recipientes). Peças de jogo (bolas de argila), pérolas e estatuetas podem sugerir tanto crenças quanto práticas divinatórias ligadas a seres não-óbvios. As estatuetas podem estar ligadas a ritos de cura e/ou de apotropia.

Kh. Raddana Site R (CALLAWAY; COOLEY, 1971, p. 14-19; LEDERMAN, 1999 , p. $72-73,140)$

$\begin{array}{lll}\text { Artefatos } & \begin{array}{l}\text { Funcionais } \\ \text { Não funcionais } \\ \text { Pessoais }\end{array} & \begin{array}{l}\text { Alça de jarro com inscrição. } \\ \text { Cratera teriomórfica. }\end{array} \\ \text { Práticas religiosas } & \begin{array}{l}\text { Libações, oferendas...? } \\ \text { Contexto religioso }\end{array} & \begin{array}{l}\text { Ritos de produção de alimentos, preocupações } \\ \text { sócio-políticas, celebrações comunitárias. }\end{array}\end{array}$

A hipótese de haver um santuário comunitário é feita principalmente pelo número de alças da "cratera de Raddana". Contudo, a evidência fragmentária não permite sugerir mais e, tampouco, decidir se este era um santuário fixo ou intrusão cerâmica.

Tell en-Nasp̣eh Room 616/622, edifício 142.04, num período posterior (ALBERTZ; SCHMITT, 2012, p. 157-159; McCOWN, 1947, p. 233, 254, 303; ZORN, 1993b, p. 653-656)

$\begin{array}{lll}\text { Artefatos } & \begin{array}{l}\text { Funcionais } \\ \text { Não funcionais } \\ \text { Pessoais }\end{array} & \begin{array}{l}\text { Tigelas, lâmpadas de pé-alto, fogueira } \\ \text { Suportes cúlticos, estatuetas antropomórficas } \\ \text { Caveira (?), morteiro cosmético }\end{array} \\ \text { Pibações, oferendas, alimentação (?), } \\ \text { Práticas religiosas } \\ \text { adivinhação (?), ritos apotropaicos (?). } \\ \text { Ritos de produção de alimentos, preocupações } \\ \text { Sócio-políticas, celebrações comunitárias, } \\ \text { apotropia, iluminação além-mundo (?). }\end{array}$

Como mencionado acima, R616/622 pode ter mudado de função com o passar dos anos. Em primeiro lugar, o prédio foi construído fora do eixo leste-oeste, não sendo originalmente religioso. O local parece ter sido utilizado por um longo período. Ao fechar a rua anelar, o edifício fere o planejamento urbano da cidade tardia, que faz interessante pensar em seu crescimento de local de culto doméstico a comunitário. 
Os locais acima cuidavam das preocupações produtivas da vila. Isso pode ser argumentado pela iconografia e pelos achados de grande porte. $\mathrm{O}$ único vestígio arquitetônico inconteste é et-Tell $L 65 / 69$, que focaliza um objeto de culto e possui rica coleção de artefatos. Dos vestígios, destaca-se o conheccido "suporte cúltico de Ai", com iconografia de patas de leão, provavelmente dos domínios de uma deusa. A estatueta de cavalo encontrada pode representar uma deusa guerreira. Refeições e oferendas compunham os rituais e as peças de jogo, pérolas e estatuetas, talvez representem ritos paralelos em homenagem à deusa, esta que parecia corresponder às preocupações produtivas da vila. $\mathrm{O}$ culto no $R S$ de Raddana, por sua vez, não tem elementos que componham um quadro amplo, mas caso se trate de local de culto, as preocupações produtivas eram centrais, embora focadas em deidade masculina.

\section{Figura 1 - Constelação "caprino sob escorpião"}

Fonte: (a) el-Jib "vinícola” (KEEL, 2013, p. 472, n. 18), (b) Nasḅeh T32 (SHUVAL, 1990, p. 108, n. 84), (c) Nasḅeh T32 (SHUVAL, 1990, p. 106, n. 78), (d) Nasḅeh T32 (KEEL, 1985, p. 37, n. 14), (e) Nasḅeh T32 (McCOWN, 1947, pl. 54.29), (f) Nasḅeh (KEEL, 1985, p. 36, n. 10), (g) Nasḅeh (KEEL, 1985, p. 37, n. 15).

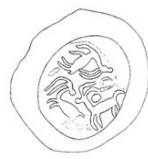

(a)

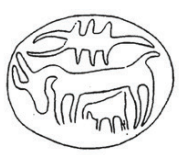

(b)

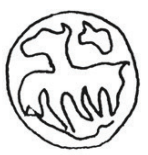

(c)

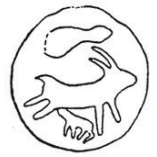

(d)

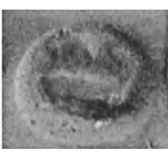

(e)

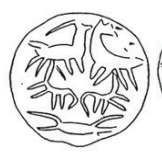

(f)

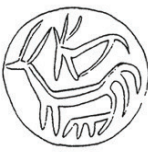

(g)

A despeito de não haver estruturas arquitetônicas, certas constelações iconográficas da região, a existência de festivais sazonais é provável. Malgrado soe dicotômico, as características ecológicas da região apontam para um festival de pastores e outro festival agrícola. O de pastores é sugerido pelo tema do "caprino amamentando sob escorpião" (Fig. 1), que sugere rituais coletivos ligados ao nascimento de novos rebanhos no surgimento da constelação de escorpião no início do inverno (STAUBLI, 2009; cf. KNAUF; GUILLAUME, 2018, p. 57-58).

\section{Figura 2 - Constelação "figuras humanas e árvore" e "figuras humanas de mãos dadas"}

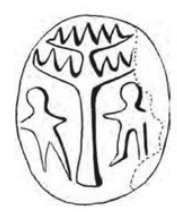

(a)

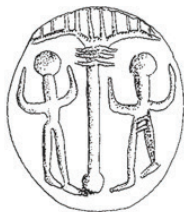

(b)

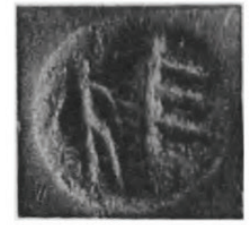

(c)

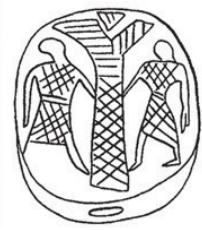

(d)

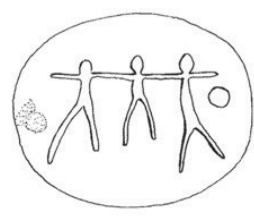

(e)

Fonte: (a) Beitin, muralha norte (KEEL, 2010, p. 28, n. 18), (b) el-Jib T3 (KEEL, 2013, p. 466, n. 3), (c) Nasḅeh T54 (McCOWN, 1947, pl. 54.47), (d) Nasḅeh (SCHROER, 2018, p. 566, n. 1581), (e) el-Jib T3 (KEEL, 2013, p. 474, n. 23). 
É possível sugerir a existência de um festival agrícola pelos temas que unem pessoas (adoradores?) flanqueando árvores (fig. 2 a-d) e de figuras humanas de mãos dadas (Fig. 2e). Enquanto o primeiro é típico dos séculos 10-9 aEC, representando o culto com árvores e cuidado materno e proteção de vivos e mortos (SCHROER, 2018, p. 326), o segundo pode representar dança (SCHACHTER, 2010, p. 152-153). Pelas práticas agrícolas da região, esses rituais celebrariam plantação e colheita de azeitonas, grãos e, talvez, uvas.

\section{Conclusão}

O presente artigo apresentou os locais de culto do platô de Benjamim na Idade do Ferro I-IIA, atentando às dissonâncias entre registro bíblico e material. Apesar da natureza e propósito diferente das fontes analisadas, a ampliação da pergunta de "templos" para "locais de práticas religiosas", provou-se produtiva para comparar as dissonâncias entre registro bíblico e material.

Em primeiro lugar, deve-se ressaltar a dissonante conotação estatal das bāmôt. A representação bíblica dos santuários como locais de encontros de chefaturas, assentos reais (1Sm 20.24-34), tal qual sua característica de traçar fronteiras regionais (1Sm 9.1-10.16) são distintas do registro material e refletem interesses retórico-ideológicos que não parecem coadunar com o registro arqueológico. Da mesma forma, enquanto no texto bíblico tais locais são associados a $y \not h w h$, o registro enfatiza uma variedade de deusas e deuses, especialmente de fertilidade e guerra, o que explorações iconográficas já demonstraram (CARDOSO, no prelo).

A taxonomia de locais parece, à primeira vista, refletir as mesmas categorias em ambos os registros. As caracterizações dos locais, contudo, destoam. Em termos tipológicos, são vistos, respectivamente no registro bíblico vs arqueológico, na esfera familiar: (a) tumbas vs casas e tumbas; e, na esfera comunitária: (b) santuários regionais vs comunitários e, no nível doméstico, (c) locais de culto a céu-aberto. A única omissão nos textos selecionados seriam santuários domésticos, o que não reflete inexistência. O mesmo não pode ser dito da caracterização entre santuários regionais bíblicos e comunitários, onde os primeiros são citadinos e centros de poder, enquanto os últimos veem saletas de culto. Isso torna difícil a existência do aparato descrito nos relatos, como as cadeiras para assentos hierárquicos, mesa etc. As práticas também são distintas. Enquanto os textos enfatizam pureza (1Sm 20.26), de teologias posteriores, o registro material sugere principalmente alimentação e divinação. Com relação aos locais abertos de culto, a descrição bíblica é por demais esquemática e as evidências materiais por demais fragmentárias para maiores comparações. 
Inusitado é o contraste entre as tumbas dos dois registros. As tumbas mencionadas em 1Sm 9.1-10.16 parecem sugerir cultos focados em matriarcas ancestrais, que cuidavam da fertilidade dos cultuantes, tal qual os atendiam e partilhavam refeições (possivelmente) por canais necromânticos. Isso não é visto no registro material, mas a ênfase a figuras maternas (deusas? matriarcas?) e preocupações produtivas surgem em locais comunitários do registro arqueológico. Embora a evidência de salas cúlticas comunitárias seja frágil, é possível questionar: seria a inversão bíblica entre práticas do espaço privado, tumbas, e público, salas de culto comunitárias, proposital? Como uma forma de diminuir a influência de mulheres no culto? Não há, infelizmente, evidências suficientes para prosseguir ou descartar a hipótese.

\section{Referências bibliográficas}

ASSMANN, J. Communicative and cultural memory. In: ERLL, A.; NÜNNUNG, A. (eds.). Cultural Memory Studies: An International and Interdisciplinary Handbook. Berlin; New

York: Walter de Gruyter, 2008, p. 109-118. (Media and Cultural Memory, 8).

ASSMANN, J. Moses the Egyptian: the memory of Egypt in Western monotheism.

Cambridge; London: Harvard University Press, 1997.

BERLEJUNG, A. Geschichte und Religionsgeschichte des antiken Israel. In: GERTZ, J. G. (ed.). Grundinformation Altes Testament. 6. ed. Göttingen: Vandenhoeck \& Ruprecht, 2019, p. 59-192. (UTB, 2745).

BLENKINSOPP, J. Gibeon and Israel: The Role of Gibeon and the gibeonites in the political a Religious History of early Israel. Cambridge: Cambridge University Press, 1972. (SOTSMS, 2).

CALLAWAY, J. A. Ai (Et-Tell): 1964-1972. BA, v. 39, n. 1, p. 18-30, mar 1976.

CALLAWAY, J. A. Ai. In: STERN, E. (ed.). The New Encyclopedia of Archaeological Excavations in the Holy Land. Vol. I. Jerusalem: IES; Carta, 1993a, p. 39-45.

CALLAWAY, J. A. Raddana, Khirbet. In: STERN, E. (ed.). The New Encyclopedia of Archaeological Excavations in the Holy Land. Vol. 4. Jerusalem: IES; Carta, 1993b, p. 12531254.

CALLAWAY, J. A.; COOLEY, R. E. A Salvage Excavation at Raddana, in Bireh. BASOR, v. 201, p. 9-19, 1971.

CARDOSO, S. K. Amuletos como mídia: poder estampado em ossos e o "Antigo Israel". Caminhando, v. 25, n. 1, p. 141-161, jan/abr 2020a.

CARDOSO, S. K. Redes mágico-míticas no alvorecer de Israel: "religião" no platô de Benjamim no Ferro I-IIA. 2019. 450 f. Tese (Doutorado em Ciências da Religião). Universidade Metodista de São Paulo, São Bernardo do Campo, 2019.

CARDOSO, S. K. The Goddesses and Gods of Saul. Pistis \& Praxis. No prelo.

CLINE, E. H. 1177 B.C.: the year Civilization collapsed. New Jersey: Princeton University Press, 2014. 
CORNELIUS, I. The study of the Old Testament and the material imagery of the ancient Near East, with a focus on the body parts of the Deity. In: JONKER, L. C. (ed.). Congress Volume Stellenbosch, South Africa. Leiden; Boston: Brill, 2017, p. 195-227. (VTSup, 177).

DAJANI, A. K. An Iron Age Tomb at al-Jib. ADAJ, v. 2, p. 66-74, 1953.

DARBY, E. Interpreting Judean pillar figurines: gender and Empire in Judean apotropaic ritual. Tübingen: Mohr Siebeck, 2014. (FAT/2, 69).

DAVIES, P. R. In search of ancient Israel: a study in biblical origins. London; New York: T\&T Clark, 2015.

ESHEL, H. The Late Iron Age cemetery of Gibeon. IEJ, v. 37, p. 1-17, 1987.

FINKELSTEIN, I. Excavations at Khirbet ed-Dawwara: an Iron Age site northeast of Jerusalem. Tel Aviv, v. 17, n. 2, p. 163-208, 1990.

FINKELSTEIN, I. First Israel, core Israel, United (Northern) Israel. NEA, v. 82, n. 1, p. 8-15, 2019.

FINKELSTEIN, I. Historical-geographical observations on the Ehud-Eglon tale in Judges. In: FINKELSTEIN, I.; ROBIN, C.; RÖMER, T. (eds.). Alphabets, texts and artifacts in the ancient Near East: studies presented to Benjamin Sass. Paris: Van Dieren, 2016, p. 100-108.

FINKELSTEIN, I. Iron Age I Khirbet Et-Tell and Khirbet Raddana: methodological lessons. In: CRAWFORD, S. W. (ed.). "Up to the Gates of Ekron". Essays on the archaeology and history of the Eastern Mediterranean in Honor of Seymour Gitin. Jerusalem: W. F. Albright Institute of Archaeological Research, 2007, p. 107-113.

FINKELSTEIN, I. Jeroboam II's temples. ZAW, v. 132, n. 2, p. 250-265, 2020.

FINKELSTEIN, I. O reino esquecido: arqueologia e história de Israel Norte. Trad. Silas Klein Cardoso e Elcio V. S. Mendonça. São Paulo: Paulus, 2015.

FINKELSTEIN, I. Tell el-Fûl revisited: the Assyrian and Hellenistic Periods (with a new identification. PEQ, v. 143, n. 2, p. 106-118, 2011.

FINKELSTEIN, I.; SINGER-AVITZ, L. Reevaluating Bethel. ZDPV, v. 125, n. 1, p. 33-48, 2009. GILBOA, A. The southern Levant (Cisjordan) during the Iron Age I Period. In:

KILLEBREW, A. E.; STEINER, M. (eds.). The Oxford Handbook of The Archaeology of Levant c. 8000-332 B.C.E. Oxford: Oxford University Press, 2013, p. 624-648.

HAMORI, E. J. Women's divination in biblical literature: prophecy, necromancy, and other arts of knowledge. New Haven; London: Yale University Press, 2015. (ABRL).

HASEL, G. F. דיגָ. In: BOTTERWECK, G. J.; RINGGREN, H.; FABRY, H. J. (orgs.). Theological Dictionary of the Old Testament. Trad. David E. Green. Grand Rapids: William B. Eerdmans Publishing, 1998, v. 9, p. 187-202.

HODDER, I. Theory and practice in archaeology. London; New York: Routledge, 1995.

HOLLADAY Jr., J, S. Religion in Israel and Judah under the monarchy: an explicitly archaeological approach. In: MILLER Jr., P. D.; HANSON, P. D.; McBRIDE, S. D. (eds.). Ancient Israelite religion. Essays in Honor of Frank Moore Cross. Philadelphia: Fortress Press, 1987, p. 249-299.

KEEL, O. Bildträger aus Palästina/Israel und die besondere Bedeutung der Miniaturkunst. In: KEEL, O.; SCHROER, S. (eds.). Studien zu den Stempelsiegeln aus Palästina/Israel Bd I. Fribourg/Suíça; Göttingen: Universitätsverlag; Vandnhoeck \& Ruprecht, 1985, p. 7-47. 
KEEL, O. Corpus der Stempelsiegel-Amulette aus Palästina/Israel: von den Anfängen bis zur Persezeit: Katalog Band II: Von Bahan bis Tel Eton. Fribourg/Suíça; Göttingen/Alemanha: Universitätsverlag; Vandnhoeck \& Ruprecht, 2010. (OBO.SA, 27).

KEEL, O. Corpus der Stempelsiegel-Amulette aus Palästina/Israel: von den Anfängen bis zur Persezeit: Katalog Band IV: Von Tel Gamma bis Chirbet Husche. Fribourg/Suíça; Göttingen/Alemanha: Universitätsverlag; Vandnhoeck \& Ruprecht, 2013. (OBO.SA, 33).

KEEL, O.; UEHLINGER, C. Göttinen, Götter und Gottessymbole: neue Erkenntnisse zur Religionsgeschichte Kanaans und Israels aufgrund bislang unerschlossener ikonographischer Quellen. 6. ed. Freiburg: Herder, 2010.

KELSO, J. L. The excavation of Bethel (1934-1960). Cambridge: American Schools of Oriental Research, 1968. (AASOR, 39).

KLETTER, R. People without Burials? The lack of Iron I Burials in the central highlands of Palestine. IEJ, v. 52, n.1, p. 28-48, 2002.

KILLEBREW, A. E. Introduction to the Levant during the transitional Late Bronze Age/ Iron Age I and Iron Age I Periods. In: KILLEBREW, A. E.; STEINER, M. (eds.). The Oxford Handbook of The Archaeology of Levant c. 8000-332 B.C.E. Oxford: Oxford University Press, 2013, p. 595-606.

KING, R. (ed.). Religion theory critique: classic and contemporary approaches and methodologies. New York: Columbia University Press, 2017, p. 1-20.

KNAUF, E. A. The impact of the Late Bronze III Period on the origins of Israel. In: GRABBE, L. L. (ed.). The Land of Canaan in the Late Bronze Age. London: Bloomsbury T\&T Clark, 2016, p. 125-132.

KNAUF, E. A.; GUILLAUME, P. A bistory of biblical Israel: the fate of the tribes and kingdoms from Merenptah to Bar Kochba. Sheffield; Bristol: Equinox, 2016. (Worlds of the Ancient Near East and Mediterranean).

KRATZ, R. G. The Idea of cultic centralization and Its supposed ancient Near Eastern analogies. In: KRATZ, R. G.; SPIECKERMANN, H. (eds.). One God, One Cult, One Nation: archaeological and biblical perspectives. Berlin; New York: Walter de Gruyter, 2010, p. 121 144. (BZAW, 405).

LANGSTON, S. M. Cultic sites in the tribe of Benjamin: Benjaminite prominence in the religion of Israel. New York: Peter Lang, 1998. (AUS, 7. Theology and Religion, 200).

LAPP, N. L. Fûl, Tell el-. In: STERN, E. (ed.). The New Encyclopedia of Archaeological Excavations in the Holy Land. Vol. II. Jerusalem: IES; Carta, 1993, p. 445-448.

LEDERMAN, Z. An Early Iron Age village at Khirbet Raddana: the excavations of Joseph A. Callaway. 1999. 168 f. Tese (Doutorado em Near Eastern Languages and Civilizations). Harvard University, Cambridge, 1999.

LEHMANN, G. Reconstructing the social landscape of early Israel: rural marriage alliances in the Central Hill Country. Tel Aviv, v. 31, n. 2, p. 141-193, 2004.

LEHMANN, G.; VARONER, O. Early Iron Age tombs in Northern Israel revisited. Tel Aviv, v. 45, n. 2, p. 235-272, 2018.

LIVINGSTONE, D. P. Kbirbet Nisya: the search for biblical Ai, 1979-2002. Excavation of the site with Related Studies in Biblical Archaeology. Pennsylvania: Masthof Press, 2012. 
LORAUX, N. Elogio do Anacronismo. In: NOVAES, A. (org.). Tempo e história. São Paulo: Companhia das Letras; Secretaria Municipal de Cultura, 1992, p. 57-70.

MANDEL, A.; SMOAK, J. The material turn in the study of Israelite religions: spaces, things, and the body. Journal of Hebrew Scriptures, v. 19, art. 5, p. 1-42, 2019.

MARQUET-KRAUSE, J. Les fouilles de 'Ay (Et-Tell), 1933-1935: la résurrection d'une grande cité biblique. BAH 45. Paris: Geuthner, 1949.

McCARTER Jr, P. K. I Samuel: new translation with introduction, notes and commentary. New Haven; London: Yale University Press, 2008. (AB, 8).

McCOWN, C. C. Tell en-Nasbeh. Excavated under the direction of the Late William Frederic Badè. Vol I: Archaeological and Historical Results. Berkeley; New Haven: The Palestine Institute of Pacific School of Religion; The American Schools of Oriental Research, 1947.

McKENZIE, S. L. Saul in the Deuteronomistic History. In: EHRLICH, C. S. (ed.). Saul in story and tradition. Tübingen: Mohr Siebeck, 2006, p. 59-70. (FAT, 47).

MEYER, B. Religion as Mediation. Entangled Religions, v. 11, n. 3, p. 1-21, 2020.

MEYER, B.; MORGAN, D.; PAINE, C.; PLATE, S. B. The origin and mission of Material Religion. In: Religion, v. 40, n. 3, p. 207-211, 2010.

MEYERS, C. Household religion. In: STAVRAKOPOULOU, F.; BARTON, J. (eds.). Religious diversity inaAncient Israel and Judah. London: Bloomsburry T\&T Clark, 2013a, p. 118-134.

MILLER, D. Introduction. In: MILLER, D. (ed.). Materiality. Durham; London: Duke University Press, 2005, p. 1-50.

MILLER II, R. D. Chieftains of the highland clans: history of Israel in twelfth and eleventh centuries B.C. Grand Rapids: Eerdmans, 2005.

NA'AMAN, N. Does archaeology really deserve the status of a "High Court" in biblical historical research? In: BECKING, B. E. J. H.; GRABBE, L. L. (eds.). Between evidence and ideology. Leiden: Brill, 2010, p. 169-183. (OS, 59).

NIDITCH, S. Ancient Israelite religion. New York: Oxford University Press, 1997.

NOLL, K. L. Canaanite religion. In: Religion Compass, v. 1, n. 1, p. 61-92, 2007.

NOLL, K. L. Canaan and Israel in Antiquity: A Textbook on History and Religion. 2. ed. London: Bloomsbury, 2013.

OLSON, D. T. Benjaminites, HB/OT. In: KLAUCK, H-. J.; LEPPIN, V.; McGINN, B.; SEOW, C-. L.; SPIECKERMANN, H.; WALFISH, B. D.; ZIOLKOWSKI, E. J. Encyclopedia of the Bible and its Reception. Vol. 3. Berlin; Boston; Walter de Gruyter, 2011, p. 866-869.

PELEG, Y.; YEZERSKI, I. A dwelling and burial cave at Kh. Abū-Musarra $\square$ in the Land of Benjamin. In: HIZMI, H.; DE GROOT, A. (eds.). Burial caves and sites in Judea and Samaria: from the Bronze and Iron Ages. Jerusalem: Israel Antiquities Authority, 2004, p. 107-156. (Judea \& Samaria Publications, 4).

PRITCHARD, J. B. Gibeon: where the sun stood still, the discovery of the biblical city. New Jersey: Princeton University Press, 1962.

RENFREW, C.; BAHN, P. Archaeology: theories, methods and practice. 7. ed rev. London: Thames \& Hudson, 2016.

ROUBEKAS, N. P. (ed.). Theorizing "Religion” in Antiquity. Sheffield: Equinox, 2019. 
SASS, B.; FINKELSTEIN, I. The swan-song of Proto-Canaanite in the ninth century BCE in light of an alphabetic inscription from Megiddo. Semitica et Classica, v. 9, p. 19-42, jan 2016. SASS, B.; FINKELSTEIN, I. The West Semitic alphabetic inscriptions, Late Bronze II to Iron IIA: archeological context, distribution and chronology. In: HeBAI, v. 2, n. 2, 2013, 149-220.

SCHACHTER, B. Dance in Iron Age Israel/Palestine 1200 - 600 B.C.: archaeological sources and Glyptic Art. In: DUMBRILL, R. (ed.). Proceedings of the International Conference of Near Eastern Archaeomusicology, ICONEA 2009-2010. London: ICONEA; Gorgias Press, 2010, p. 143-159.

SCHNIEDEWIND, W. M. A social history of Hebrew: Its origins through the Rabbinic Period. New Haven; London: Yale University Press, 2013. (AYBRL).

SCHROER, S.; KEEL, O. Die ikonographie Palästinas/Israels und der Alte Orient. eine Religionsgeschichte in Bildern. Band 1: Vom ausgehenden Mesolithikum bis zur Frühbronzezeit. Fribourg: Schwabe; Bibel + Orient Museum, 2005.

SCHROER, S. Die ikonographie Palästinas/Israels und der Alte Orient: eine Religionsgeschichte in Bildern. Bd. 4: Die Eisenzeit bis zum Ende der achämenidischen Herrschaft. Gesamtregister. Fribourg: Schwabe; Bibel + Orient Museum, 2018.

SCHUNCK, K.-D. Benjamin: Untersuchungen zur Entstehung und Geschichte eines israelitischen Stammes. Berlin: Verlag Alfred Töpelmann, 1963. (BZAW, 86).

SCHUNCK, K.-D. Benjamin (Person). In: FREEDMAN, D. N. (org.). The Anchor Yale Bible Dictionary. Vol. 1. New York: Doubleday, 1992, p. 671-673.

SHUVAL, M. A Catalogue of Early Iron stamp seals from Israel. In: KEEL, O.; SHUVAL, M.; TIGAY, J. H. You shall have no other gods: Israelite religion in the light of Hebrew inscriptions. Atlanta: Scholars Press, 1986, p. 67-162.

SILVA, J. L. F. Arqueologia e semiótica do espaço dos templos de Judá em seu contexto levantino. 2018. 471 f. Tese (doutorado em Arqueologia). Museu de Arqueologia e Etnologia da Universidade de São Paulo, São Paulo, Brasil, 2018.

STAUBLI, T. Bull leaping and other images and rites of the Southern Levant in the sign of Scorpius. Ugarit-Forschungen, v. 41, p. 611-630, 2009.

STAVRAKOPOULOU, F. Land of our fathers: the roles of ancestor veneration in Biblical Land claims. New York: Bloomburry T\&T Clark, 2012. (LHBOTS, 473).

STAVRAKOPOULOU, F. "Popular" religion and "Oficial” religion: practice, perception, portrayal. In: STAVRAKOPOULOU, F.; BARTON, J. (eds.). Religious diversity in ancient Israel and Judah. London: Bloomsburry T\&T Clark, 2013, p. 37-58.

TOORN, K.V. D. Family religion in Babylonia, Syria and Israel: continuity and change in the forms of religious life. Atlanta: SBL Press, 1996. (SHCANE, 7).

UEHLINGER, C. Beyond "Image Ban" and "Aniconism": reconfiguring ancient Israelite and Early Jewish religion $\backslash \mathrm{s}$ in a visual and material religion perspective. In: STORDALEN, T.; MEYER, B. (eds.). Figuration and sensation of the unseen in Judaism, Christianity and Islam: contested desires. London: Bloomsbury Academic, 2019, p. 99-123. (Bloomsbury Studies in Material Religion).

UEHLINGER, C. Bildquellen und „Geschichte Israels“ Grundsätzliche Überlegungen und Fallbeispiele. In: HARDMEIER, C. (ed.). Steine, bilder, texte: historische evidenz 
außerbiblischer und biblischer Quellen. Leipzig: Evangelische Verlagsanstalt, 2001, p. 25-77. (ABG, 5).

UEHLINGER, C. Distinctive or diverse? Conceptualizing ancient Israelite religion in its southern Levantine setting. In: HeBAI, v. 4, 2015, p. 1-24.

WAMPLER, J. C. Tell en-Nasbeh. Excavated under the direction of the Late William Frederic Badè. Vol II, The Pottery. Berkeley; New Haven: The Palestine Institute of Pacific School of Religion; ASOR, 1947.

ZERTAL, A. The Manasseb Hill Country Survey: Vol. 2. The Eastern Valleys and the Fringes of the Desert. Leiden; Boston: Brill 2008. (CHANE, 21.2)

ZEVIT, Z. The religions of ancient Israel: a synthesis of parallactic approaches. New York: Continuum, 2001.

ZORN, J. R. Nasḅeh, Tell en-. In: STERN, E. (ed.). The New Encyclopedia of Archaeological Excavations in the Holy Land. Vol. III. Jerusalem: IES; Carta, 1993a, p. 1098-1102.

ZORN, J. R. Tell en-Nasbeb: a re-evaluation of the architecture and stratigraphy of the Early Bronze Age, Iron Age and later periods. Vol I-IV. 1993. 1707 f. Tese (Doutorado em Near Eastern Studies). Graduate Division of the University of California, Berkeley, 1993b.

ZWICKEL, W. Der Tempelkult in Kanaan und Israel: studien zur Kultgeschichte Palästinas von der Mittelbronzezeit bis zum Untergang Judas. Tübigen: Mohr Siebeck, 1994. (FAT 10).

Submetido em: 14-7-2020

Aceito em: 21-9-2020 